\section{oin a leading \\ 6 community \\ hospital!}

The Brantford General Hospital, a 200+ bed acute care facility, boasts stable, state-of-the-art programs within a team environment and has a dedicated staff that ensures high level patient-focused care.

Located in the picturesque Grand River Valley, Brantford is a family-centered community with affordable housing and exceptional recreational opportunities. An easy commute to large urban centres such as Toronto, Hamilton, Kitchener, and London affords our staff many alternatives in shopping and entertainment, as well as access to seven major universities.

Dr. W.A. Lloyd-Smith, Chief Department of Anaesthesia The Brantford General Hospital 200 Terrace Hill Street Brantford, Ontario N3R 1G9

Tel: (519) 751-5508

Fax: (519) $751-5550$

\section{Anaesthetist - Full \& Part-time}

Brantford, Ontario needs a full-time and a part-time certified Anaesthetist to join seven others in our community.

The Department of Anaesthesia staffs two hospitals, one of which is slated to close. All procedures will be performed at the Brantford General Hospital in a new surgical suite which will be completed by 2002. Call duty is approximately one in seven. Surgical specialities include all except thoracic, cardiac, and neurosurgery. The Department provides obstetrical services. Children under one year are referred to teaching centres elsewhere. Involvement in ICU and pain clinics is optional.

\section{Join a congenial grouplotaff in Southern Ontarial}

For more information please contact us!

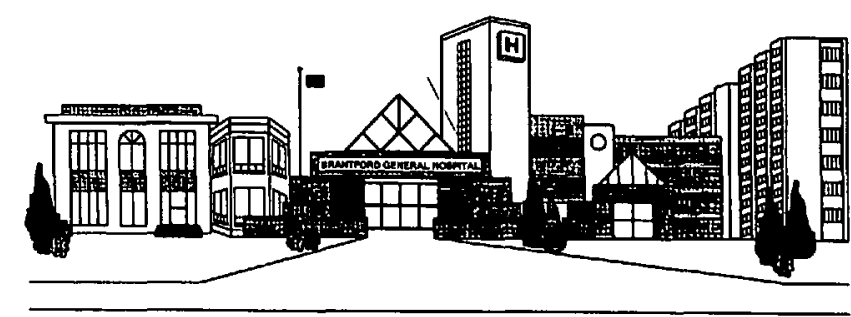

BRANTFORD GENERAL HOSPITAL

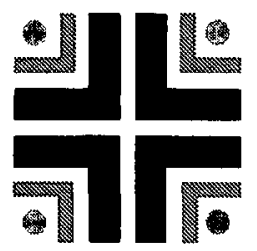

\title{
THUNDER BAY REGIONAL HOSPITAL requires
}

ANAESTHETISTS

The department of Anaesthesia of the Thunder Bay Regional Hospital is looking for full-time anaesthetists to join a group of 9 anaesthetists practicing in the two city hospitals. We perform over 14,000 anaesthetics annually for all specialties except cardiac. A new hospital is currently being built on the Lakehead University campus and is scheduled to open in 2002.

This is a young dynamic department and we are looking for candidates who will assist us in developing our services as we expand. Thunder Bay is designated as an underserviced area for anaesthesia and new staff are eligible to receive a $\$ 20,000$ tax free incentive grant. Locum anaesthetists are reimbursed for accommodation and travel expenses and receive a substantial daily stipend in addition to OHIP billings. Candidates must have FRCP certification and Canadian citizenship or landed immigrant status.

Thunder Bay is a community of 130,000 and the referral center for all of Northwestern Ontario. It is the home of Lakehead University, Confederation College and we have our own symphony, a performing arts centre and several theatre groups. We have superb outdoor recreational facilities including three downhill ski facilities, a national crosscountry ski training center, a yacht club on Lake Superior, and thousands of lakes for fishing, canoeing, etc. Thunder Bay also has an international airport with direct flights to Minneapolis, Toronto, and Western Canada.

This is a unique opportunity for someone wishing to combine a challenging professional practice with a relaxed lifestyle on the edge of the Ontario wilderness.

Please direct inquiries related to this exciting opportunity to:

Dr. Ian Dobson

Chief, Department of Anaesthesia

Thunder Bay Regional Hospital

idobson@baynet.net

(807) 343-7023 